Vocational Behavior

Elsevier Editorial System(tm) for Journal of

Manuscript Draft

Manuscript Number: JVB-12-473

Title: General mental ability and personality traits as predictors of early career success.

Article Type: Regular Article

Keywords: General mental ability, personality, career success, salary, job satisfaction.

Corresponding Author: Mr. JOSE MANUEL DE HARO,

Corresponding Author's Institution: AGBAR (SUEZ ENVIRONEMENT)

First Author: JOSE MANUEL DE HARO, DEGREE IN PSYCHOLOGY

Order of Authors: JOSE MANUEL DE HARO, DEGREE IN PSYCHOLOGY; JUAN LUIS

CASTEJON, PH D in psycholgy.; RAQUEL GILAR, PH D in psycholgy.

Abstract: In this paper, we examine the effects of general mental ability (GMA) and the personality traits defined in the big five model on extrinsic and intrinsic indicators of career success, in a sample of 130 graduates who were in the early stages of their careers. Results from hierarchical regression analyses indicated that GMA does not predict any of the success indicators. In contrast, the combination of GMA and three of the Big Five Personality traits, conscientiousness, neuroticism, and openness, is significantly associated with greater early career success and has incremental predictive validity. 


\section{To the Editor-in-chief of Journal of Vocational Behaviour.}

\section{Title: General mental ability and personality traits as predictors of early career} success

The overall results of this study show that in the early career stage, career success, measured as salary and career satisfaction, was predicted by interactions between personality variables and general mental ability (GMA). Neither GMA nor personality traits alone predicted early career success as well as interactions did. Specifically, salary was predicted negatively by neuroticism and openness, and by interactions between Conscientiousness x IQ, Neuroticism x IQ, and Openness x IQ, whereas career satisfaction was predicted negatively by Openness, and by the interaction between Conscientiousness $x$ IQ. These interactions explained $11 \%$ of the variance over GMA and personality traits for salary and $9 \%$ for career satisfaction.

Recommendations for future research include incorporating ability x motivation models among predictors, as well as other personal and emotional intelligence variables and situational factors such as occupational characteristics. Furthermore, a comparison should be conducted of the results obtained in samples of professionals at the start of their careers with those obtained for samples of professionals with more experience.

Authors: José Manuel de Haro García, Juan Luis Castejón Costa and Raquel Gilar Corbí.

University of Alicante. Department of Educational Psychology and Didactic. Campus de San Vicente del Raspeig, E-03080 Alicante, Spain.

* Corresponding author. Tel.: +34 965903400. E-mail addresses: jmharo@ua.es; (José Manuel de Haro). 
IQ does not predict any of the success indicators.

Personality traits, conscientiousness, neuroticism, and openness, are significantly associated with greater early career success.

Personality traits, have incremental predictive validity over GMA. 


\title{
General mental ability and personality traits as predictors of early career success
}

\begin{abstract}
:
In this paper, we examine the effects of general mental ability (GMA) and the personality traits defined in the big five model on extrinsic and intrinsic indicators of career success, in a sample of 130 graduates who were in the early stages of their careers. Results from hierarchical regression analyses indicated that GMA does not predict any of the success indicators. In contrast, the combination of GMA and three of the Big Five Personality traits, conscientiousness, neuroticism, and openness, is significantly associated with greater early career success and has incremental predictive validity.
\end{abstract}

Key words: General mental ability, personality, career success, salary, job satisfaction.

Corresponding author: Juan Luis Castejón Costa. Department of Developmental and Educational Psychology, University of Alicante. Campus de San Vicente del Raspeig. Apartado de correos 99, 03080 Alicante. E-mail: jl.castejon@ua.es.

Phone number: 034965903400 ext 3861 


\title{
General mental ability and personality traits as predictors of early career success
}

\begin{abstract}
:
In this paper, we examine the effects of general mental ability (GMA) and the personality traits defined in the big five model on extrinsic and intrinsic indicators of career success, in a sample of 130 graduates who were in the early stages of their careers. Results from hierarchical regression analyses indicated that GMA does not predict any of the success indicators. In contrast, the combination of GMA and three of the Big Five Personality traits, conscientiousness, neuroticism, and openness, is significantly associated with greater early career success and has incremental predictive validity.
\end{abstract}

Key words: General mental ability, personality, career success, salary, job satisfaction.

\section{Introduction.}

As research studies have shown, general mental ability (GMA) predicts job performance across occupations, contexts and careers (Bertua, Anderson \& Salgado, 2005; Dreher \& Bretz, 1991; Judge, Cable, Boudreau \& Bretz, 1995; Kuncel, Hezlett \& Ones, 2004; Ng, Eby, Sorensen \& Feldman, 2005; Salgado, Moscoso, de Fruyt, Anderson, Bertua \& Rolland, 2003; Schmidt \& Hunter, 2004).

However, although some authors believe that GMA is the most useful employee attribute for predicting job performance, explaining up to half the variance in occupational level in complex and higher level jobs (Schmidt \& Hunter, 2004), it is not advisable to use it as the sole predictor. There are other factors that provide incremental 
validity in predicting labor outcomes (Bobko, Roth \& Potosky, 1999), indicating the desirability of including these as predictors, in addition to general intelligence.

Of the alternative predictive factors studied, personality traits in particular have received considerable attention due to their proven importance in predicting effective performance in different occupations (Ariza, 2001; Boudreau, Boswell \& Judge, 2001; Cherniss, 2001). Factors such as self-esteem, proactiveness, locus of control, selfefficacy, self-control, optimism, Machiavellianism, occupational status and occupational self-efficacy have been shown to have positive relationships with career success criteria (Abele \& Spurk, 2009; Eby, Butts \& Lockwood, 2003; Ng et al., 2005).

From among the personality variables, those based on the Five Factor Model have attracted the most research attention in both traditional and meta-analytic studies in the United States and the European Community (Boudreau et al., 2001, Ng et al., 2005; Salgado, 1998). The association known as "the big-five salary link" indicates that employees with a certain personality trait profile work harder and earn a higher salary (Barrick \& Mount, 1991; Dilchert \& Ones, 2008; Gelissen \& de Graaf, 2006; Hülsheger, Specht \& Spinath, 2006; Judge et al. 1999; Ng et al. 2005; Nyhus \& Pons, 2005; Seibert \& Kraimer 2001; Tett, Jackson \& Rothsten, 1991).

Despite these findings, the search for the best predictors of career success has not been without its difficulties and uncertainties. In order to establish a system of clear relationships between predictors and criteria, it is necessary to address questions concerning the use of different types of measures, criteria and samples in different occupations and organizations. 
This paper is intended to answer some of these questions in order to help clarify the interrelationships and contributions of GMA and personality traits to early career success.

The first question that arises is twofold. On the one hand, we wanted to determine whether the predictive superiority of GMA over all other factors was maintained in the case of professionals at the start of their careers, and on the other hand we wished to ascertain whether the predictive power of GMA differed according to whether we used extrinsic or intrinsic success criteria.

As regards the first aspect, although it would be logical to assume that intelligence would be the most important factor at the start of a career, since this is when employees must learn procedures, the few studies which have been conducted (O’Reilly \& Chatman, 1994; Rode et al., 2008) have found no direct relationship between abilities and career success in the early career stage.

As for the relationship between GMA and extrinsic success factors such as salary or career advancement, the associations with mental ability have ranged from slightly positive to moderate (Dreher \& Bretz, 1991; Judge, Higgins, Thoreson \& Barrick, 1999; Ng et al., 2005). Meanwhile, the correlations obtained between mental ability and intrinsic success criteria such as job satisfaction were negative or non significant (Ganzach, 1998; Rode et al., 2008).

In our study, we hypothesized that high levels of GMA would enable employees to acquire important job knowledge, which in turn would lead to improved performance, and postulated that those new employees who learned more efficiently in the early stages of their careers would achieve greater career success. For these reasons, 
in the first hypothesis we did not differentiate between the results on the basis of extrinsic or intrinsic success criteria:

Hypothesis 1: General mental ability is positively related to initial career success for extrinsic and intrinsic career success criteria.

A second issue is whether intelligence is more important than personality factors in career success, or whether personality has incremental validity over intelligence. Although it would appear that personality traits contribute significantly to earnings and status attainment (Gelissen \& De Graaf, 2006), some authors believe that the incremental validity is nevertheless limited (McHenry, Hough, Toquam, Hanson \& Ashworth, 1990; O’Boyle, Humphrey, Pollack, Hawver \& Story, 2011). However, other authors have found that, controlling for general mental ability, personality is related to career success (Judge et al., 1999). In our study, we hypothesized that personality would add significantly to the variance contributed by GMA.

Hypothesis 2: Personality traits have incremental validity over GMA in predicting initial career success.

Thirdly, we wished to determine the relationship between personality factors and success criteria in the early career stage, i.e., to identify the factors which best predicted both types of success criteria. To this end, we analyzed the main results reported in the literature which, with the exception of some contradictory data possibly due to the statistical methods used (Goldberg, 1993), suggest that responsibility and extraversion are positively although modestly associated with job performance, salary and career 
advancement, whereas neuroticism and agreeableness are negatively associated (Barrick \& Mount, 1991; Boudreau et al., 2001; García-Izquierdo, García-Izquierdo \& RamosVillagrasa, 2007; Gelissen \& De Graaf, 2006; Judge et al., 1999; Ng et al., 2005; Rode et al., 2008; Salgado, 1998; Smithikrai, 2007; Spurk \& Abele, 2011; Tett et al., 1991).

As regards the first of the big five personality traits, "conscientiousness", although a few studies have obtained a negative relationship between this dimension and status mobility in women (Boudreau et al., 2001; Gelisson \& De Graaf, 2006), most results indicate a positive relationship between conscientiousness, salary and job satisfaction (Barrick \& Mount, 1991; Judge at al., 1999; Judge, Heller \& Mount, 2002; Judge \& Kammeyer-Mueller, 2010; Sutin, Costa, Miech \& Eaton, 2009), leading to our third hypothesis.

Hypothesis 3: Conscientiousness is positively related to initial career success.

All studies focusing on neuroticism have found that this factor correlates negatively with both intrinsic and extrinsic success criteria (Boudreau et al., 2001; Gelissen \& De Graaf, 2006; Judge et al., 1999; Judge et al., 2002; Judge \& KammeyerMueller, 2007; Ng et al., 2005; Nyhus \& Pons, 2005; Rode at al., 2008; Seibert \& Kraimer, 2001; Salgado, 1998; Smithikrai, 2007; Sutin et al., 2009). The negative relationship between career success and factors such as hostility, depression, social anxiety, impulsiveness and vulnerability, and the association between these and neuroticism, led us to propose our fourth hypothesis.

Hypothesis 4: Neuroticism is negatively related to initial career success. 
Meanwhile, the positive relationships found between extraversion and success criteria as regards both salary (Gelissen \& De Graaf, 2006; Judge et al., 1999; Judge \& Kammeyer-Mueller, 2010; Rode et al., 2008; Seibert \& Kraimer, 2001; Sutin et al., 2009) and satisfaction (Boudreau et al., 2001; Judge et al., 2002; Seibert \& Kraimer, 2001) led us to propose our fifth hypothesis.

Hypothesis 5: Extraversion is positively related to initial career success.

Although agreeableness can be an advantage in positions requiring interaction with other people, most studies have found a negative relationship between this factor and career success measured as salary (Boudreau et al., 2001; Judge et al., 1999; Ng et al., 2005; Nyhus \& Pons, 2005; Rode et al., 2008; Seibert \& Kraimer, 2001). As regards satisfaction, a positive relationship has generally been obtained between this and agreeableness (Bozionelos, 2004; Judge et al., 2002), although negative relationships have also been found (Seibert and Kreimer, 2001). For occupational level, negative relationships (García-Izquierdo et al., 2007) and non significant relationships have been obtained (Gelissen \& De Graaf, 2006) between both. For other criteria, such as job performance (Hurtz \& Donovan, 2000; Sutin et al., 2009) or success in job seeking, the associations obtained have been positive (Boudreau et al., 2001). A negative relationship is predicted in the following hypothesis.

Hypothesis 6: Agreeableness is negatively related to initial career success.

The results obtained in studies on openness have been inconsistent. There appears to be a positive relationship with job performance ( $\mathrm{Ng}$ et al., 2005; Tett et al., 
1991; Van der Linden, Te Nijenhuis \& Bakker, 2010), although negative associations have also been found (Furnham, Taylor \& Chamorro-Premuzic, 2008). In contrast, the majority of studies have found a negative relationship between openness and salary (Bozionelos, 2004; Gelissen \& De Graff, 2006; Seibert \& Kreimer, 2001) or no association at all (Barrick \& Mount, 1991; Boudreau et al., 2001), compared to those which found positive relationships (Palifka, 2009). Results for job satisfaction have also been varied, ranging from studies which found no relationship (Judge, et al, 2002) or a slightly positive association (Boudreau et al., 2001), to those which have obtained positive relationships (Eby et al., 2003; Sutin et al., 2009). In this study, we proposed a negative relationship between openness and success criteria, postulating that too much openness in the early career stage can contribute negatively to the achievement of greater career success.

Hypothesis 7: Openness is negatively related to initial career success.

The last question we wished to analyze was whether the relationship between GMA and career success was mediated by any of the personality factors, and in particular, whether it might vary depending on levels of conscientiousness, neuroticism and openness.

We included these interactions on the basis of considerations such as those formulated in industrial and organizational psychology "expectance models", which conceptualize performance as the interaction between ability and effort (motivation). The decision to include these three factors alone rather than all of the personality traits was based on an analysis of the findings on their intervention as part of a larger motivational construct, and on the argument about their role in job performance which 
suggests that the more stable and responsible an individual is and the less open, the more able that person will be to generate higher motivational concentration, leading to greater achievement.

The relationship between motivation and ability has been highlighted in several studies. Hollenbeck, Brief, Whitener \& Pauli (1988) have provided evidence of a multiplicative relationship between motivation and ability in affecting outcomes. Meanwhile, Dreher \& Bretz (1991) observed that GMA only influenced performance when motivation was considered.

As in the study by Schmidt \& Hunter (1992), we postulated that conscientiousness may come to be viewed as the most important motivational trait variable in the work domain. Interesting results have been obtained when conscientiousness is included together with variables of ability; in their study of social status (income and professional status), Amelang \& Steinmayr (2006) found that general intelligence and conscientiousness had approximately the same significant influence on the two performance criteria, while the meta-analytical structural equation modeling performed by $\mathrm{Ng} \&$ Feldman ( 2010) showed that an individual's cognitive ability and conscientiousness mediate the effects of both education and organizational tenure on in-role and extra-role job performances.

The rationale behind the inclusion of neuroticism is its repeated negative weight as an individual difference variable and its association with other variables such as anxiety, self-control, emotional stability and social skills, which are linked to dimensions of emotional intelligence and in some cases have been found to interact with IQ when predicting job performance (Coté \& Miners, 2006) or with GMA for salary (Ferris, Witt \& Hochwarter, 2001). Openness has been included among the possible mediating variables due to the inconsistent results obtained for this factor as a predictor, 
and the fact that it forms part of the general personality factor known as plasticity (Van der Linden et al., 2010). Agreeableness and extraversion were not included in the study, because of consistent results indicating an indirect influence on salary (Spurk \& Abele, 2011) and because their content appears to be less closely connected to the meaning of a motivational construct.

Very little empirical research has been conducted on the interaction effects of cognitive and personality variables on job performance in the early career stage, with inconclusive results. Some studies have found evidence of interaction (O'Reilly \& Chatman, 1994) and others have not (Rode et al., 2008). In their study of a sample of recent MBA graduates, O'Reilly and Chatman (1994) found that neither GMA nor the motivational trait of conscientiousness alone was a good predictor of early management success. In contrast, their interaction was the strongest predictor of early career success for MBA graduates. Thus, the combination of high general cognitive ability and high motivation is significantly associated with greater early career success. On the other hand, in a sample of organizational behavior students, Rode et al. (2008) did not find any evidence of interaction effects, only observing relationships between agreeableness (negative), extraversion (positive) and salary and perceived career success.

Given these inconsistencies, in our last three hypotheses we wished to test the interaction of conscientiousness, neuroticism, openness with GMA as predictors of early career success, postulating that GMA would act as a moderator of these relationships.

Hypothesis 8: As an indicator of GMA, IQ moderates the relationships between conscientiousness and initial career success. 
Hypothesis 9: IQ moderates the relationships between neuroticism and initial career success.

Hypothesis 10: IQ moderates the relationships between openness and initial career success.

\section{Method}

\subsection{Participants}

The study was conducted on a sample of 130 university graduates who were in employment at the time of the study. Of these, $35.9 \%$ were women and $64.1 \%$ men, with a mean age of 26.4 years (standard deviation 4.38). The sample consisted of graduates who reported they were working, in a survey conducted of 339 university graduates from the University of Alicante (Spain) three years after completion of their studies. These 339 students had participated three years earlier in a study that assessed their personal and socio-emotional competences, having been selected through a stratified random sampling system proportional to the number of students enrolled in each of the fields of science and technology (25.7\%), social sciences (18.9\%), education $(24.5 \%)$, bio-health (15.9\%) and humanities $(6.5 \%)$.

\subsection{Measures}

2.2.1. Test of "g", Scale 3, by R. B. Cattell \& A. K. S. Cattell (Spanish adaptation by Técnicos Especialistas Asociados, 1994)

To measure general mental ability, we used the test of "g", Scale 3 by R.B. Cattell and A.K.S. Cattell (adapted to Spanish by Técnicos Especialistas Asociados, 1994). This collectively applied scale consists of four subtests: series, classification, 
matrices and conditions, which require cognitive operations such as identification, perceived similarities, seriation, classification, matrices and comparisons, enabling us to obtain the IQ of the sample. The "g" factor loadings are high, around 0.90 .

\subsubsection{Big Five Inventory (NEO-FFI, Costa \& McCrae, 1992)}

This is a self-report measure of five personality dimensions: Extraversion, Agreeableness, Consciousness, Neuroticism and Openness. The short version consists of 60 elements. Participants indicate their level of agreement with each item on a 5point Likert scale $(1=$ strongly disagree, $5=$ strongly agree). The reliability of the Spanish version ranges between 0.82 for agreeableness and 0.90 for neuroticism, similar to the English version.

\subsubsection{Career success criteria}

To assess extrinsic career success, we used the items corresponding to salary from a specific questionnaire based on the employment questionnaires developed as part of the CHEERS and REFLEX studies, which collect detailed information on aspects such as the degree course studied, transition from education to employment, first job following graduation, employment history, current post and the competences considered essential for entry to the labor market. The questionnaire consisted of 43 questions organized into seven sections covering various aspects related to training received, transition to employment, competences and satisfaction, among others. Salary level was measured as gross monthly income, divided into seven categories: less than 600 Euros (1), between 600 and 1000 Euros (2), between 1000 and 1200 Euros (3), between 1200 and 1500 Euros (4), between 1500 and 1800 Euros (5), between 1800 and 2000 Euros (6) and more than 2000 Euros (7). 
The intrinsic criterion of success (career satisfaction) was obtained from the sum of responses to items 30, 37 and 39, which assessed the degree of satisfaction with their careers on a 5 -point scale where $1=$ low and $5=$ high. Cronbach's alpha of internal consistency was 0.79 .

\subsection{Procedure}

In the first phase, conducted when students were enrolled in the final year of their degree course, the NEO-PIR questionnaire were administered together with other tests, to an initial sample of 906 subjects. Three years after the first study conducted in 2010, the initial sample was reduced to 339 graduates, comprising those who continued to participate after graduation by completing a questionnaire designed to collect information about the employment status of the graduates studied previously and their entry to the workforce. The questionnaire, which required no more than 30 minutes to fill in, was administered online to be completed within a maximum period of three months from receipt.

\subsection{Design and data analysis}

A predictive correlational design was used, and data were analyzed using hierarchical multiple regression. The calculations were performed using SPSS version 19, licensed to the University of Alicante. The MODPROBE tool (Hayes \& Matthes, 2009) was used to probe the interactions.

\section{Results}

Correlations between all measures, mean and standard deviations are shown in Table 1 . As can be seen from this table, IQ was significantly and negatively correlated with neuroticism (-.23) and positively with extraversion (.29), but not with either salary 
or career satisfaction. Only one of the personality factors, neuroticism, was associated, negatively, with salary (-.24).

\section{Insert table 1.}

To examine the predictive and incremental validity of the Big Five personality traits dimension and the interactions proposed above, the effect of IQ on "Salary" and "Career satisfaction", we performed hierarchical regression analyses (Table 2). For each regression model, a career success criterion (salary or career satisfaction) was the dependent variable, and IQ, personality traits, and interactions were considered as independent variables (step $1=$ IQ; step $2=$ personality traits; step 3 = Conscientiousness $\mathrm{x}$ IQ; Neuroticism $\mathrm{x}$ IQ, and Openness $\mathrm{x}$ IQ). Following the guidelines described by Aiken \& West (1991) and Friedrich (1982) to estimate interaction effects using multiple regression, all variables were transformed into $\mathrm{z}$ standardized scores, and significance was assessed using unstandardized coefficients.

\section{Insert table 2.}

As can be seen in Table 2, in step 2, significant effects were only found for neuroticism on salary $(\mathrm{B}=-.23, p<.05)$ and openness on salary $(\mathrm{B}=-.21, p<.05)$ and satisfaction ( $\mathrm{B}=-.24, p<.05)$, but the change in $\mathrm{F}$ did not achieve statistical significance $(p=.06)$. In contrast, the introduction of interactions in step 3 produced an increase in explained variance of $11 \%$ for salary and $9 \%$ for career satisfaction. 
Conscientiousness, extraversion, and agreeableness were not significantly related to any of the criteria; neuroticism was significantly and negatively related to salary ( $\mathrm{B}=-.29$, $p<.01)$ but not with career satisfaction, and openness was significantly and negatively related to salary $(\mathrm{B}=-.25, p<.05)$ and career satisfaction $\mathrm{B}=-.27, p<.05)$.

All interactions were negative. The significant negative coefficients associated with the interaction terms indicate that the relationships between predictive personality variables and career success tended to be more negative for individuals with higher GMA, as evidenced by IQ. Interactions between Conscientiousness $\mathrm{x}$ IQ were negatively related to salary $(\mathrm{B}=-.29, p<.05)$ and career satisfaction $(\mathrm{B}=-.30, p<.05)$. Interactions between Neuroticism x IQ and Openness x IQ were only related to salary ( $\mathrm{B}=-.23 p<.05$ and $\mathrm{B}=-.22, p<.05$, respectively).

Probing the interactions using the MODPROBE tool (Hayes \& Matthes, 2009) provided additional information for the interpretation of these conditional effects. To assess the effect of predictor variables on salary and career satisfaction at specific conditional values of the moderator, we computed simple slopes at the mean and at 1sd above and 1sd below the mean. In addition, the regions of significance were established using the Johnson-Newman technique (Johnson \& Newman, 1936).

Taking salary as the criterion, the simple slope of salary regressed on conscientiousness was positive and significant only at low IQ ( $b=.36, p=.03)$, specifically at $\mathrm{IQ}=94$, whilst at high $\mathrm{IQ}$ the slope was negative $(\mathrm{b}=-.14, p=.38)$ and not significant. The simple slope on neuroticism was negative and significant at average $(b=$ $-.25, p=.02)$ and high IQ $(\mathrm{b}=-.38, p=.01)$, specifically from IQ $=98$, and the simple slope of salary regressed on openness was negative and significant at average $(b=-.22$, $p=.04)$ and high IQ $(\mathrm{b}=-.45, p=.00)$, specifically from $\mathrm{IQ}=102$. Taking career satisfaction as the criterion, the simple slope of career satisfaction regressed on 
conscientiousness was positive and significant only at low IQ $(b=.39, p=.02)$, specifically at $\mathrm{IQ}=97$.

By way of example, Figures 1 and 2 show the interaction Conscientiousness $x$ IQ for each criterion, salary and career satisfaction, with raw scores for the measured variables.

\section{Insert figure 1.}

\section{Insert figure 2.}

\section{Discussion}

The overall results of this study show that in the early career stage, career success, measured as salary and career satisfaction, was predicted by interactions between personality variables and general mental ability (GMA). Neither GMA nor personality traits alone predicted early career success as well as interactions did. Specifically, salary was predicted negatively by neuroticism and openness, and by interactions between Conscientiousness $\mathrm{x}$ IQ, Neuroticism x IQ, and Openness $\mathrm{x}$ IQ, whereas career satisfaction was predicted negatively by Openness, and by the interaction between Conscientiousness x IQ. These interactions explained $11 \%$ of the variance over GMA and personality traits for salary and $9 \%$ for career satisfaction.

Slightly different results were observed for each of the criteria considered, where the weight of the variables studied was greater for salary than for career satisfaction, indicating that although they shared similarities and served as indicators of career success, they reflected different components of success. 
In addition to this general finding, a more detailed review and analysis of the results of this study indicates the following.

First, mental ability did not predict either salary or career satisfaction in the early career stage. On the basis of these results, which differ from those found by Judge et al. (1999) and Ng et al. (2005) but are consistent with those reported by Rode et al. (2008), hypothesis 1 can be rejected. Contrary to what might be expected, greater mental ability is not required for learning processes and procedures specific to a given position in the early career stage. This would seem to imply that at this stage of a career, there are other factors which are more influential than intellectual ability. However, the importance of mental ability cannot be discounted since its impact may increase over the years, as indicated by Mc Daniel et al. (1988). Another possible explanation for the results is that mental ability does not exert a direct effect but rather, it mediates personality traits. As will be discussed below, this second view seems to be supported by the data obtained in our study.

As regards the negative association found between IQ and neuroticism, this could be explained by the mediating effect of anxiety, as has been suggested by Moutafi, Furnham \& Tsaousis (2006). The significant positive relationship found between IQ and extraversion is consistent with most of the results obtained in other studies, as indicated for example in the meta-analysis conducted by Wolf \& Ackerman (2005).

Second, the effects of personality traits on career success after controlling for the effects of GMA were not significant, contrary to the findings reported in studies such as those by Judge et al. (1999) and Gelissen \& De Graaf (2006). Thus, hypothesis 2 is not 
supported, leaving the door open to other variables, such as emotional intelligence, which may add significant variance over GMA (O'Boyle et al., 2011).

Third, the only personality factors associated with career success in the early career stage were neuroticism (salary) and openness (salary and career satisfaction), both of which presented negative relationships with these criteria, thus confirming hypothesis 7 and partially confirming hypothesis 4 .

In the case of neuroticism, these findings are consistent with most of the studies mentioned in the introduction and confirm the potentially negative effect of interference from concerns about achieving the occupational goals that lead to career success (salary). This relationship did not occur in the case of career satisfaction, which suggests that greater stability is not necessarily associated with greater career satisfaction, perhaps because subjects were still at the start of their career. Different results might be obtained after a longer period of time.

The results obtained in the present study for openness support studies that report a negative relationship between this factor and career success (Bozionelos, 2004; Gelissen \& De Graff, 2006; Seibert \& Kraimer, 2001). Greater concentration in the early career stage seems crucial for success. Lack of focus or excessive attention to different interests would be counterproductive, except in the case of artistic or creative positions.

In contrast to the studies cited in the introduction, we found no evidence of a relationship between the other personality traits and medium or long-term career success criteria. In our study, conscientiousness, extraversion and agreeableness showed no relationship with success in the early career stage, and thus hypotheses 3,5 and 6 are not supported. Of these, the most unexpected result, given the evidence reported to date, 
was the non-intervention of conscientiousness as a predictor for any of the criteria. However, it should be borne in mind that these employees had not been working for very long, and for tenacity to influence outcomes it is possibly necessary to have accumulated more experience. A regards the lack of a relationship between the other two factors, extraversion and agreeableness, one possible explanation could be that social or interpersonal aspects are less important in the early career stage, since employees are not usually in charge of others at this stage in their career, and perform many tasks individually. Another explanation for these results may be that these factors exert their influence indirectly rather than directly, as indicated in the research by Spurk \& Abele (2011).

Lastly, the interactions between the personality traits considered in the study (conscientiousness, neuroticism and openness) and GMA showed the strongest effect on career success; consequently, the effects of these personality variables on salary and career satisfaction are moderated by level of intelligence. These results are consistent with those reported by O'Reilly and Chatman (1994) for a similar sample, and indicate the strength of the interactions, although in our case the associations between the interactions and the criteria were negative. In addition, the effects of Neuroticism $x$ IQ and Openness $\mathrm{x}$ IQ on career satisfaction were not significant, and thus hypotheses 8,9 and 10 are only partially supported.

The form and significance of interactions shows that in the case of Conscientiousness $\mathrm{x}$ IQ, conscientiousness becomes a stronger predictor of career success as IQ decreases. In other words, employees with low levels of cognitive intelligence obtain a better salary and are more satisfied with their careers if they are more tenacious, self-disciplined, organized and methodical. In contrast, for subjects with a medium or high IQ, greater or lesser conscientiousness does not lead to greater 
success. These results are similar to those found by Coté and Miners (2006) for the effect of emotional intelligence on job performance, and imply that effort may compensate for low levels of mental ability.

In the case of neuroticism, the results indicate that employees with medium to high cognitive intelligence obtain a higher salary if they are more emotionally stable and less anxious, impatient and careless. Finally, and with respect to openness, the results indicate that employees with medium to high cognitive intelligence obtain a higher salary if they are less dreamy, idealistic and imaginative, and when their range of interests is more limited. For these two variables, having a low IQ did not affect any of the criteria.

These findings are inconsistent with the results obtained by Rode et al., (2008) and by Chamorro-Premuzic \& Arteche (2008), who stated that the effects of responsibility on employment outcomes are largely independent of intellectual ability. In contrast, our results suggest the need to include interactions between ability and personality variables as predictors of selection and promotion processes in the early career stage, since if only abilities or aspects of personality are considered, the capacity to identify candidates who may achieve career success in the middle to long term could be severely hampered, leading to false negative results.

As indicated in the introduction, these interactions may form part of a motivational construct which in this case would act as a proximal rather than distal variable in determining career success (Spurk \& Abele, 2011). Therefore, rather than asking whether GMA exerts more influence than personality, it would be more appropriate to explore whether it does so directly or indirectly, for example through personality traits. 
Recommendations for future research include incorporating ability x motivation models among predictors, as well as other personal and emotional intelligence variables and situational factors such as occupational characteristics. Furthermore, a comparison should be conducted of the results obtained in samples of professionals at the start of their careers with those obtained for samples of professionals with more experience.

\section{References}

Abele, A. E., \& Spurk, D. (2009). The longitudinal impact of self- efficacy and career goals on objective and subjective career success. Journal of Vocational Behavior, $74,53-62$.

Aiken, L. S., \& West, S. G. (1991). Multiple Regression: Testing and interpreting interactions. Newbury Park, CA: Sage.

Amelang M., \& Steinmayr R. (2006). Is there a validity increment for tests of emotional intelligence in explaining the variance of performance criteria?. Intelligence 34, 459-68.

Ariza, J. A. (2001). Competencias emocionales y mercado de trabajo: un enfoque empírico. Estudios financieros. Revista de Trabajo y Seguridad Social: Recursos Humanos, 220, 175-202.

Barrick, M. R. \& Mount. M. (1991). The Big Five Personality Dimensions and Job Performance: A Meta-Analysis. Personnel Psychology, 4, 1-26.

Bertua, C., Anderson, N. R., \& Salgado, J. (2005). The predictive validity of cognitive ability tests: A UK meta-analysis. Journal of Occupational and Organizational Psychology, 78, 387-409.

Bobko, P., Roth, P. L., \& Potosky, D. (1999). Deviation and implications of a metaanalytic matrix incorporating cognitive ability, alternative predictors, and job performance. Personnel Psychology, 52, 561-589.

Boudreau, J. W., Boswell, W. R., \& Judge, T. A. (2001). Effects of personality on executive career success in the United States and Europe. Journal of Vocational Behavior, 58, 53-81. 
Bozionelos, N. (2004). Mentoring provided: Relation to mentor's career success, personality, and mentoring received. Journal of Vocational Behavior, 64(1), 2446.

Cattell, R. B., \& Cattell, A. K. S. (1994). Test de Factor «g» de Cattell, Escala 2 (Forma A). Institute for personality and ability testing. Spanish adaptation. Madrid, Spain: TEA Ediciones, S.A.

Cherniss, C. (2001). Social and Emotional Competence in the Workplace. In R. Bar-On \& J.D. Parker (eds.). The Handbook of Emotional Intelligence (pp. 391-410). San Francisco, CA: Jossey- Bass.

Costa, P. T., \& McCrae, R. R. (1992). Revised NEO Personality Inventory (NEO PI-R) and NEO Five-Factor Inventory (NEO-FFI): Professional manual. Odessa, FL: Psychological Assessment Resources.

Coté, S., \& Miners, C. (2006). Emotional Intelligence, Cognitive Intelligence and Job Performance. Administrative Science Quarterly 51,1-28.

Dilchert, S., \& Ones, D. S. (2008). Personality and extrinsic career success: Predicting managerial salary at different organizational levels. Personalpsychologie, 7, 1-23.

Dreher, G. F., \& Bretz, R. (1991). Cognitive ability and career attainment: Moderating effects of early career success. Journal of Applied Psychology, 76, 392-397.

Eby, L. T., Butts, M., \& Lockwood, A. (2003). Predictors of success in the era of the boundaryless career. Journal of Organizational Behavior, 24, 689-708.

Ferris G. R., Witt L. A., \& Hochwarter W. A. (2001). Interaction of social skill and general mental ability on job performance and salary. Journal of Applied Psychology, 86, 1075-1082.

Friedrich, R.J. (1982). In defense of multiplicative terms in multiple regression equations. American Journal of Political Science, 26, 797-833.

Furnham, A., Taylor, J., \& Chamorro-Premuzic, T. (2008). Personality and intelligence correlates of assessment center exercise. Individual Differences Research, 6, 181192.

Ganzach, Y. (1998). Intelligence and job satisfaction. Academy of Management Journal, $41,526-539$. 
García-Izquierdo, A.L., García-Izquierdo, M., \& Ramos-Villagrasa, P.J. (2007). Inteligencia Emocional y Autoeficacia. Aportaciones para la selección de personal. Anales de Psicología, 23, 231-239.

Gelissen, J., \& De Graaf, P. M. (2006). Personality, social background, and ccupational career success. Social Science Research, 35, 702-726.

Hayes, A. F., \& Matthes, J. (2009). Computational procedures for probing interactions in OLS and logistic regression: SPSS and SAS implementations. Behavior Research Methods, 41, 924-936.

Hollenbeck, J. R., Brief, A. P., Whitener, E. M., \& Pauli, K. E. (1988). An empirical note on the interaction of personality and aptitude in personnel selection. Journal of Management, 14, 441-451.

Hülsheger, U. R., Specht, E., \& Spinath, F. M. (2006). Validitat des BIP und des NEOPI-R: Wie geeignet sind ein berufsbezogener und ein nicht explizit berufsbezogener Persönlichkeitstest zur Erklaung von Berufserfolg [BIP and NEO-PI-R: Predictive validity of an occupational vs. general personality test]. Zeitschrift fur Arbeits- und Organisationspsychologie, 50, 135-147.

Informe ejecutivo REFLEX (2007). El profesional flexible en la Sociedad del Conocimiento: Nuevas exigencias en la Educación Superior en Europa. [The Flexible Professional in the Knowledge Society: New Demands on Higher Education in Europe]. Agencia Nacional de Evaluación de la Calidad y Acreditación (ANECA). Ministerio de Educación y Ciencia, Madrid, Spain.

Johnson, P.O., \& Neyman, J. (1936). Tests of certain linear hypotheses and their application to some educational problems. Statistical Research Memoirs, 1, 57-93.

Judge, T. A., Cable, D. M., Boudreau J. W., \& Bretz, R. D. (1995). An empirical investigation of the predictors of executive career success. Personnel Psychology, 48, 485-519.

Judge, T. A., Higgins, C. A., Thoreson, C. J., \& Barrick, M. R. (1999). The Big Five personality traits, general mental ability, and career success across the life span. Personnel Psychology, 52, 621- 52.

Judge, T. A., Heller, D., \& Mount, M. K. (2002). Five-factor model of personality and job satisfaction: A meta-analysis. Journal of Applied Psychology, 87, 530-541. 
Judge, T. A., \& Kammeyer-Mueller, J. D. K. (2010). Implications of core selfevaluations for a changing organizational context. Human Resource Management Review, 1-11.

Hurtz, G. M., \& Donovan, J. J. (2000). Personality and job performance: The big five revisited. Journal of Applied Psychology, 85, 869-879.

Kuncel, N.R., Hezlett, S.A., \& Ones, D.S. (2004). Academic performance, career potential, creativity, and job performance: Can one construct predict them all?. Journal of Personality and Social Psychology, 86, 148-161.

McHenry, J. J., Hough, L. M., Toquam, J. L., Hanson, M. A., \& Ashworth, S. (1990). Project A validity results: The relationship between predictor and criterion domains. Personnel Psychology, 43, 335-354.

Ng, W. H., Eby, L. T., Sorensen, K. L., \& Feldman, D. C. (2005). Predictors of objective and subjective career success. A meta-analysis. Personnel Psychology, $58,367-408$.

Nyhus, E. K., \& Pons, E. (2005). The effects of personality on earnings. Journal of Economic Psychology, 26, 363-384.

O’Boyle, E. H., Humphrey, R. H., Pollack, J. M., Hawver, T. H., \& Story, P. A. (2011). The relation between emotional intelligence and job performance: A metaanalysis. Journal of Organizational Behavior, 32, 788-818.

O’Reilly, C. A., \& Chatman, J. A. (1994). Working smarter and harder: a longitudinal study of managerial success, Administrative Science Quarterly, 39, 603-627.

Palifka, B. J. (2009). Personality and income in Mexico: Supervisor assessments vs. Self-assessments. Journal of Economic Psychology, 30, 92-106.

Rode, J. C., Arthaud-Day M. L., Mooney' C. H., Near' J. P., \& Baldwin T. T. (2008) Ability and Personality Predictors of Salary, Perceived Job Success, and Perceived Career Success in the Initial Career Stage. International Journal of Selection and Assessment, 16(3), 292-299.

Salgado, J. F. (1998). Big Five personality dimensions and job performance in army and civil occupations: a European perspective. Human Performance, 11, 271-88

Salgado, J., Moscoso, S., De Fruyt, F., Anderson, N., Bertua, C., \& Rolland, J. (2003). A Meta-Analytic Study of General Mental Ability Validity for Different Occupations in the European Community, Journal of Applied Psychology. 88(6), $1068-1081$. 
Schmidt, F L. \&. Hunter. J.1998. The Validity and Utility of Selection Methods in Personnel Psychology: Practical and Theoretical Implications of 85 Years of Research Findings. Psychological Bulletin 124(2), 262-274.

Schmidt, F. L., \& Hunter, J. (2004). General mental ability in the world of work: Occupational attainment and job performance. Journal of Personality and Social Psychology, 86, 162-173.

Schomburg, H. \& Teichler, U. (2003). CHEERS Project Results. Higher Education and Graduate Employment in Europe. Results of Graduate Surveys from 12 Countries. Dordrecht: Kluwer Academia Publishers (in press). Recuperado el día 20/11/2012 en http://www.uni-kassel.de/wz1/proj/edwork/mat/manual_es.pdf. *****

Schomburg, H. \& Teichler, U. (2006). CHEERS Projects Results. Higher Education and Graduate Employment in Europe. Results from Graduate Surveys from Twelve Countries. Dordrecht, Netherlands: Springer.

Seibert, S. E., \& Kraimer, M. L. (2001). The five-factor model of personality and career success. Journal of Vocational Behavior, 58,1-21.

Smithikrai, C. (2007). Personality traits and job success: An investigation in a Thai sample, International Journal of Selection and Assessment, 15(1), 134-138.

Spurk, D., \& Abele, A. E. (2011). Who earns more and why? A multiple mediation model from personality to salary. Journal of Business and Psychology, 26, 87-103

Sutin, A. R., Costa, P. T., Jr., Miech, R., \& Eaton, W. W. (2009). Personality and career success: Concurrent and longitudinal relations. European Journal of Personality, $23,71-84$.

Tett, R. P., Jackson, D. N., \& Rothstein, M. (1991). Personality measures as predictors of job performance: A meta-analytic review. Personnel Psychology, 44, 703-742.

Van der Linden, D., Te Nijenhuis, J., \& Bakker, A. B. (2010). The general factor of personality: A meta-analysis of Big Five intercorrelations and a criterion-related validity study. Journal of Research in Personality, 44, 315-327. 
Table 1. Correlation matrix of all measures and descriptive statistics.

\begin{tabular}{lcccccccc}
\hline & 1 & 2 & 3 & 4 & 5 & 6 & 7 & 8 \\
\hline 1. IQ & 1 & & & & & & & \\
2. Neuroticism & $-.23^{*}$ & 1 & & & & & & \\
3. Extraversion & $.29^{* *}$ & $-31^{* *}$ & 1 & & & & & \\
4. Openness & -.01 & -.05 & $.22^{*}$ & 1 & & & & \\
5. Agreeableness & -.08 & -.18 & $.21^{*}$ & $.35^{* *}$ & 1 & & & \\
6. Conscientiousness & .01 & $-.26^{* *}$ & $.23^{*}$ & $.23^{*}$ & $.30^{* *}$ & 1 & & \\
7. Salary. & .01 & $-.24^{*}$ & .06 & -.17 & -.00 & .12 & 1 & \\
8. Career satisfaction & .00 & -.12 & .11 & -.15 & .07 & .14 & $.57^{* *}$ & 1 \\
\hline Means & 102.4 & 31.9 & 45.6 & 43.22 & 41.45 & 46.2 & 1372 & 9.49 \\
Standard deviation & 15.5 & 8.3 & 6.7 & 7 & 6.9 & 6.3 & 536 & 2.6 \\
\hline
\end{tabular}

Table 2. Results of hierarchical multiple regression analyses of initial career success

\begin{tabular}{|c|c|c|c|c|}
\hline & \multicolumn{2}{|c|}{ Salary } & \multicolumn{2}{|c|}{ Career satisfaction } \\
\hline & $\mathrm{B}$ & $\Delta \mathrm{R}^{2}$ & B & $\Delta \mathrm{R}^{2}$ \\
\hline Step 1: Mental ability & & $.00(p=.89)$ & & $.00(p=.93)$ \\
\hline IQ & .01 & & .01 & \\
\hline Step 2: Personality traits & & $.11(p=.06)$ & & $.08(p=.17)$ \\
\hline IQ & -.05 & & -03 & \\
\hline Neuroticism & $-.23 *$ & & -.06 & \\
\hline Extraversion & .04 & & .11 & \\
\hline Openness & $-.21 *$ & & $-.24 *$ & \\
\hline Agreeableness & -.01 & & .08 & \\
\hline Conscientiousness & .11 & & .13 & \\
\hline Step 3: Interactions & & $.11 * *(p=.00)$ & & $.09 *(p=.03)$ \\
\hline IQ & .03 & & .04 & \\
\hline Neuroticism & $-.29 * *$ & & -.11 & \\
\hline Extraversion & .03 & & .11 & \\
\hline Openness & $-.25 *$ & & $-.27 *$ & \\
\hline Agreeableness & -.00 & & .08 & \\
\hline Conscientiousness & .09 & & .12 & \\
\hline Conscientiousness x IQ & $-.29 *$ & & $-.30 *$ & \\
\hline Neuroticism x IQ & $-.23 *$ & & -.20 & \\
\hline Openness x IQ & $-.22 *$ & & -.15 & \\
\hline Total adjusted $\mathrm{R}^{2}$ & & .22 & & .17 \\
\hline
\end{tabular}




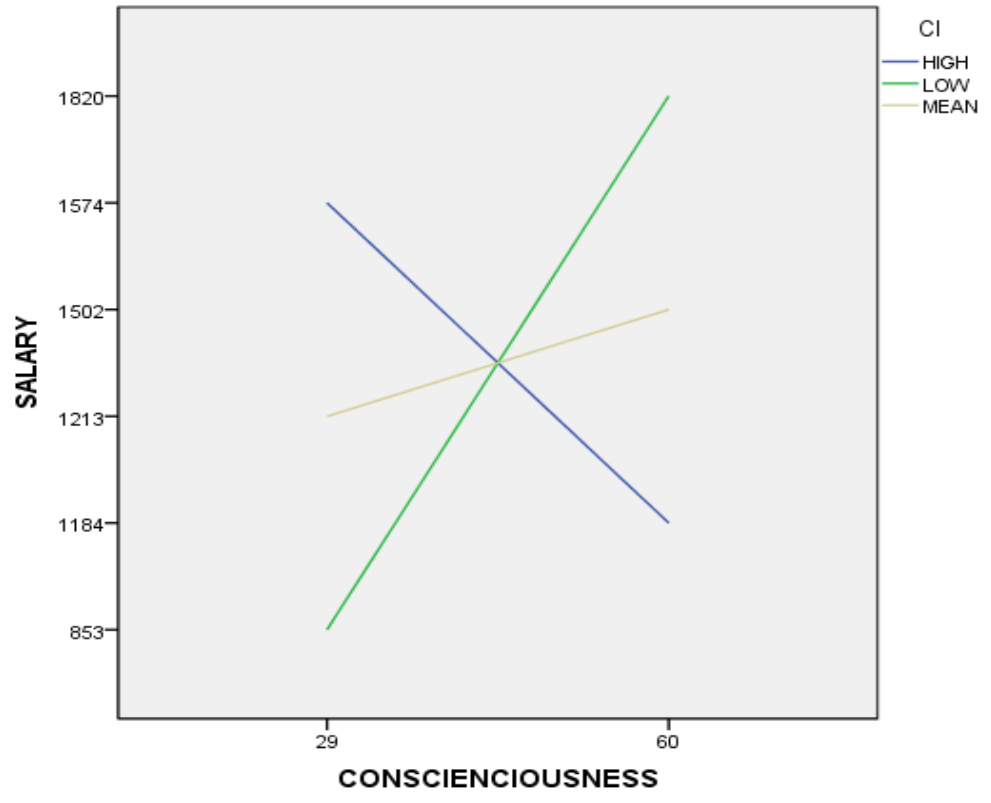

Figure 1. Interaction between Conscientiousness and IQ in predicting salary.

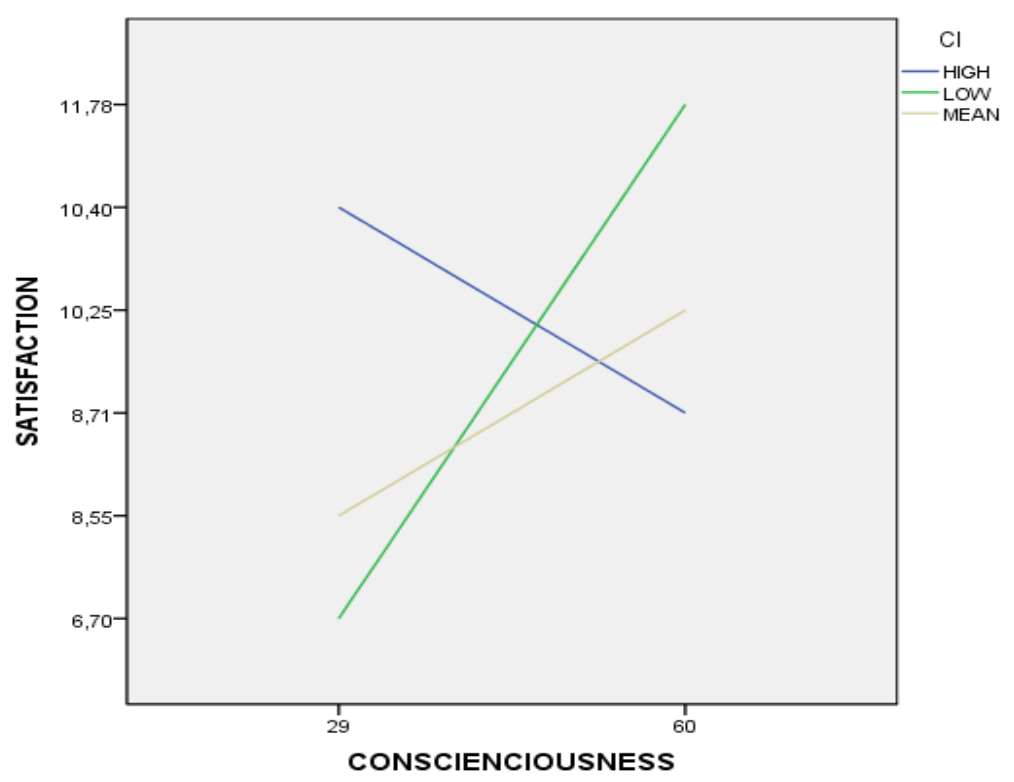

Figure 2. Interaction between Conscientiousness and IQ in predicting career satisfaction. 